\title{
Understanding of learning styles and teaching strategies towards improving the teaching and learning of mathematics
}

Jose M. Cardino Jr. ${ }^{1}$ and Ruth A. Ortega-Dela Cruz ${ }^{2}$

${ }^{1}$ Department of Education, Division of Los Baños, Laguna, Philippines

2 University of the Philippines Los Baños, Laguna, Philippines

This study was conducted to analyse the influence of learning styles and teaching strategies on academic performance in mathematics. Surveys were conducted to 277 randomly selected grade 9 students and five purposively sample mathematics teachers. Findings reveal that most of the student-respondents have a combination of dependent, collaborative and independent learning styles. Multiple regression analysis indicates that among the learning styles, only the independent style has a significant influence on the academic performance of grade 9 students. Four teaching strategies including cooperative learning, deductive approach, inductive approach, and integrative approach, were found to have a significant influence on academic performance. By understanding the learning styles of students, teachers will be guided in designing different strategies to help students enhance learning for their improved performance in mathematics.

Keywords: learning styles, mathematics, performance, secondary, teaching strategies

\author{
Article Details \\ LUMAT General Issue \\ Vol 8 No 1 (2020), 19-43 \\ Received 10 February 2020 \\ Accepted 4 May 2020 \\ Published 25 May 2020 \\ Pages: 25 \\ References: 47 \\ Correspondence: \\ raortegadelacruz@up.edu.ph \\ https://doi.org/10.31129/ \\ LUMAT.8.1.1348
}

\section{Introduction}

Mathematics plays a predominant role in everyday life. Learning mathematics helps students think analytically and have better reasoning abilities. It helps them develop their lifelong learning skills to solve problems in life. Academically speaking, mathematics is a subject that many students either love or hate. It is hated by learners who do not find figures interesting, especially those students who are more into social sciences (Prayoga \& Abraham, 2017). Most students perceive mathematics subjects negatively (Zakaria, Solfitri, Daud \& Abidin, 2013; Fonseca, 2007). Because of the formula and rules involved in a mathematics lesson, students tend to develop negative attitudes and concern towards the subject (Altintas \& Ilgün, 2017). Many students struggle with learning mathematics at some point. For this reason, they have to experiment with different learning styles in learning mathematics. The learning styles of the students define how they respond to stimuli in the context of learning.

According to Keefe (1979 in Ariola, 2012), "learning style is the composite of characteristics of cognitive, affective and psychological factors that serve as relatively stable indicators of how a learner perceives, interacts with, and responds to the learning environment.” According to Stewart and Felicetti (1992), learning is 
influenced by the educational conditions under which a student learns. Therefore, learning style is not just concerned about what students need to learn but rather how they want to learn in the most effective way.

One of the most significant challenges in learning is for individuals to take responsibility for their own learning. When learners take responsibility for their own learning, they attribute meaning to the process of learning, leading to effective learning (Nzesei, 2015). Teachers need to understand the process of individual learning. In the learning process, individuals are interacting with the environment, i.e., uniquely processing the information and requiring a unique environment for learning. Thus, addressing the challenge in facilitating learning conditions while organizing such interactions should be taken into consideration to help individuals to optimize their learning (Sighn, 2017).

To bring a fundamental change in the learner is the primary purpose of teaching at any level of education (Tebabal \& Kahssay, 2011). Teachers should apply appropriate teaching strategies that best suit specific objectives and competencies to secure and facilitate the process of knowledge transmission.

In the past decades, many educators widely applied teacher-centred strategies to impart knowledge to learners' comparative to student-centred strategies. Until today, questions about the effectiveness of teaching strategies on student learning have consistently raised considerable interest in the thematic field of educational research (Hightower, Delgado, Lloyd, Wittenstein, Sellers \& Swanson, 2011). Moreover, researches on teaching and learning constantly endeavour to examine the extent to which different teaching strategies enhance growth in student learning.

Effective teaching requires flexibility, creativity, and responsibility in order to provide an instructional environment able to respond to the learner's individual needs. Tomlinson (2001 in Tulbure, 2012) puts it beyond the experiential evidence that pervasive uniformity in teaching fails many learners. There is a reason in both theory and research to support a movement towards an instruction attentive to students' variance manifested in at least three areas: the student's readiness, interest, and learning profile. Nowadays, one of the challenges in teaching-learning process is knowing the most effective teaching approach and strategies that are also in line with the learning styles of the students. Recent researches indicate the following teaching strategies are common and effective in teaching mathematics: cooperative learning (Javed, Saif \& Kundi, 2013), lecture type, deductive approach (Baig, 2015), inductive approach (Atta, Ayaz \& Nawaz, 2015; Padmavathy \& Mareesh, 2013), demonstrative 
approach (Ramadhan \& Surya, 2017), repetitive exercises (Warthen, 2017), and integrative approach (Panicker, 2014).

Aside from learning styles and teaching strategies, academic achievement is also considered as the centre of interest in educational research. Studying the issue of achievement has extended beyond simple to complex issues of intelligence and prior academic achievement into how learners interact with the learning material and teaching strategies.

This issue on academic achievement is particularly true in the case of the Philippine basic education, as reflected in the overall performance of the high school students. Results of the National Achievement Test (NAT) among public high schools all over the country had been declining since 2010 (Valdez, 2016). NAT is just one of the country's criteria for measuring students' academic achievement in mathematics. The Philippine NAT results provide continuous documentation of the need to put greater emphasis on improving the teaching and learning of mathematics in the country. The question is: what more must be done and taken into greater account to be able to improve the academic performance of high school students in mathematics?

This study sought answers to this major concern. The researchers believe that by understanding the influence of learning styles and teaching strategies, educators will find effective ways to improve academic performance in mathematics. This also tried to fill in the gap in terms of the researches that look closely into the contribution of these key variables on the students' performance in mathematics.

The study presented in this paper specifically (i) determined the profile of the students in terms of sex, the average grade in mathematics and learning styles (ii) determined teaching strategies applied by the teachers in teaching mathematics; and (iii) analysed the influence of learning styles and teaching strategies on the academic performance in mathematics.

\subsection{Theoretical framework}

According to Samadi (2011), studies about the learning styles started in the 1950s and in the early 1960 s due to interest in the effect of the individual differences in the learning process. One of the famous learning styles models is Grasha-Riechmann Learning Styles Model. This model integrates individual teaching and learning styles and demonstrates how the stylistic qualities of teachers and students can enhance the nature and quality of the learning experience (Grasha, 1996). It is based on the notion that to maximize learning; one must truly understand individual learning styles. To 
do this, differences in student attitudes must be taken into account. Grasha (1996) identified six distinct learning styles based on the individual student's attitude towards learning. These proposed six styles can be changed by the consistent use of one teaching method. Grasha also proposed that students naturally select the most productive style. Avoidant students tend to be at the lower end of the grade distribution. They tend to have high absenteeism, they organize their work poorly, and they take little responsibility for their learning. Participative students are characterized by their willingness to accept responsibility for self-learning and relate well to their peers. Competitive students are described as suspicious of their peers leading to competition for rewards and recognition. Collaborative students enjoy working harmoniously with their peers. Dependent students typically become frustrated when facing new challenges not directly addressed in the classroom. Independent students prefer to work alone and require little direction from the teacher.

However, Grasha and Hicks (2000 in Shaari, Yusoff, Ghazali, Osman \& Dzahir, 2014) argue that to ensure the effectiveness of a teaching and learning process, teaching strategies also need to be considered as an important element in the success of a lesson. These teaching strategies are the pattern of belief, knowledge, performance, and behavior of teachers when they are teaching (Grasha, 1996).

According to Hamzeh (2014), there are several teaching strategies that can be used by teachers to improve the academic performance of the students in mathematics. Those teaching strategies are accounted for in different time periods and applied inside the classroom. The most common one is lecture type. It is an instructional method where the teacher who possesses the knowledge on a given topic delivers all relevant information to students verbally. The person presenting the lecture was called a reader because the information in the book was read to students who would then copy the information all down (Goffe \& Kauper, 2014). Cooperative learning is a simple strategy that allows students to work and solve a problem with a pair or a group (Razak, 2016). When a teacher has provided the basic instruction, $\mathrm{s} /$ he will then split the class into pairs or groups to work on problems (Chan \& Idris, 2017). Since the pairs are working as a team, the students can discuss the problems and work together to solve them. The goal of cooperative learning is to teach students critical thinking skills that are necessary for future math problems and real life (Sari, Mulyono, \& Asih, 2019; Zakaria, Solfitri, Daud \& Abidin, 2013). A simple strategy teacher can use to improve math skills is repetition or repetitive exercise. By 
repeating and reviewing previous formulas, lessons, and information, students are better able to comprehend concepts at a faster rate (Bates, 2020). According to Wilson (1999), the core concepts of basic math must be mastered before students are able to move into a more advanced study. Repetition is a simple tool that makes it easier for students to master concepts without wasting time. A strategy which connects other subject matter in other subject area is called integrative approach. This is another way of organizing those learnings that came from another subject area and making an instructional design be interesting and integrative (Panicker, 2014). In this strategy, all the factors that can contribute to the teaching-learning process are considered (Adunola, 2011). Demonstration method of teaching is another form of traditional classroom strategy that requires step by step process of solving math problems (Ramadhan \& Surya, 2017). It focuses on achieving psychomotor and cognitive objectives. Another approach that teaches the students to learn how to learn rather than what to learn is induction. This is an effective approach for helping students to understand concepts and generalizations and for developing their higher-orderthinking skills (Rahmah, 2017). The inductive approach is a much more studentcentred approach that makes use of a strategy known as 'noticing.' Here, various facts and examples are presented to the learners from where they have to find out rules or establish a general formula. Therefore, it is a method of constructing a formula with the help of an adequate number of concrete examples (Singh \& Yadav, 2017). Meanwhile, the deductive approach is the opposite of the inductive approach, where the teacher conducts lessons by introducing and explaining concepts to students and then expecting students to complete tasks to practice the concepts. In this approach, all the general ideas or information are given to the students and the specific ideas or information are discussed later (Singh \& Yadav, 2017; Adunola, 2011).

The researchers used the Grasha-Riechmann Learning Styles Model because it is an approach that focuses on how personal attributes (e.g., belief, knowledge, performance, behavior and even motivation) influence strategies, approaches and concepts associated with effective teaching and learning (Coffield, Moseley, Hall \& Ecclestone, 2004). The model has been studied and has been found practical across a variety of educational settings. For instance, using Grasha-Riechmann Learning Styles Model, Azarkhordad and Mehdinezhad (2016) found that teaching methods based on cooperation could create opportunities to achieve educational goals and provide access to higher mental activity. Thus, they concluded that by strengthening 
cooperative and participative learning styles, teachers could improve levels of student learning. Ford, Robinson, and Wise (2016) adapted the Grasha-Riechman Student Learning Style Survey and Teaching Style Inventory to assess individual teaching and learning styles in a quality improvement collaborative. They found that individual learners and coaches utilize multiple approaches in the teaching and practice-based learning of quality improvement (QI) processes. They suggested that to improve the organizational processes and outcomes, efforts to accommodate learning styles need to be taken into consideration. Baneshi, Tezerjani, and Mokhtarpour (2014) investigated the psychometric properties of the Grasha-Riechmann Student Learning Styles Scale and found that the Participative Styles Scale to be an instrument qualifying validity and reliability for measuring interactive learning styles. Baneshi, Karamdoust, and Hakimzadeh (2013) investigated the male and female students' learning styles of classroom participation and these styles' differences between Humanities and Science majors. They concluded that female students tend to collaborate with other students of the same sex and participate in their activities. In terms of their major, science students are more participative and collaborative than humanities students because they need more collaboration in their projects and course work. Gujjar and Tabassum (2011) used the Grasha-Riechmann learning style survey to determine the learning styles of student teachers at the Federal College of Education in order to develop teaching strategies in them. Their findings showed a significant difference in all the dimensions of learning styles among the classes and that dependent learning style was found to be the best learning style for the studentteachers.

\section{Materials and methods}

\subsection{Research design}

The descriptive-correlational research design was used in the study. Descriptive research simply describes the characteristics and/or behaviour of the sample population. (Dudovskiy, 2016).

\subsection{Subjects of the study}

The subjects of the study were composed of a randomly selected sample of 277 Grade 9 students in a public high school in Laguna, Philippines. They were drawn from a population of 910 regular students from 18 classes with varied types of students. The 
study employed proportional allocation of student-respondents using the fishbowl method to get the representatives from each class.

For the selection of teachers, purposive sampling was done since there were only five Grade 9 mathematics teachers who handled the 277 students for the School Year (S.Y.) 2017- 2018.

\subsection{Instrumentation}

The data utilized for the study were the survey scores of Grasha-Riechmann Learning Styles Scales (GRLSS) (1996). The reliability coefficient numbers of the 6 subdimensions pointed in the theory of the inventory was found to be medium and the validity coefficient numbers of the 6 learning styles mentioned in the inventory were found to be good (Grasha,1996). The Teaching Strategies Questionnaire was adapted in the study of Hamzeh (2014). The adapted teaching strategies survey tool was undergone with a test of validity and a test of reliability. For the test of validity, the tool was presented to the five (5) faculty members of Education Sciences College, Jordan. The researcher conducted a test of reliability with a test-retest and CronbachAlpha method, and the result got a total degree (0.89) with a reliability factor of 'good.' Moreover, the researchers conducted a similar test of reliability and got the same result. Cronbach's Alpha for the total scale was obtained as 83 percent while its subscales were obtained from 45 percent to 73 percent. The GRLSS is a pre-designed 6o-item questionnaire, each with a 1 to 5 -point Likert Scale, which is as follows: $1-$ strongly disagree, 2 - disagree, 3 - moderately agree, 4 - agree and 5 - strongly agree. While in teaching strategies, there are 49 situations that were evaluated according to the 1 to 5-point Likert scale as follows: 1 - Never, 2 - Seldom, 3 - Sometimes, 4 often and 5 - always (see Appendix 1).

Looking at the GRLSS and teaching strategies, it can be seen that each style or strategy is described by different characteristics. Based on the description, the questions and situations in both survey tools were manually grouped according to learning style and teaching strategies. For learning styles, the Avoidant is related to items $2,8,14,20,26,32,38,44,50,56$; the Collaborative is under $3,9,15,16,22,28$, 34, 40, 46, 52, 58; Competitive can be seen on $5,11,17,23,29,35,41,47,53,59$; Dependent assigned to numbers $4,10,16,22,28,34,40,46,52,58$; next to it is Independent in numbers $1,7,13,19,25,31,37,43,49,55$; and lastly Participant is reflected in numbers $6,12,18,24,30,36,42,48,54$, 60. The Teaching Strategies Questionnaire has corresponding situations for each strategy. These are as follow: 
Cooperative learning assigned numbers include 16, 21, 29, 37, 38, 39, 43; Demonstration includes 4, 11, 19, 27, 28, 35, 49; Deductive approach includes 5, 12 , 14, 18, 26, 34, 36; Inductive approach includes 1, 7, 13, 17, 20, 42, 48; Integrative approach includes 2, 8, 10, 23, 30, 33, 41; Lecture type includes 3, 22, 25, 32, 40, 44, 46 and lastly those remaining statements are for Repetitive exercise including 6, 9, 15 , $24,31,45,47$.

On the other hand, the scoring key was provided where the ratings assigned for each test item were indicated. The sum of each learning style statements and strategy statements determined the learning style of the students and teaching strategies applied by their teachers.

\subsection{Data collection}

The items of the questionnaires assessed students' and teachers' profiles, learning styles, and teaching strategies. After seeking permission, the researcher personally administered the questionnaires in a paper-and-pencil format. The survey administration was done after the classes. Two sets of survey questionnaires were adapted. The first set was a five-point Likert scale that determined the learning styles of the students. While the other set of survey-questionnaire was used to identify the teaching strategies applied by their teachers. In addition to primary data, secondary data such as the students' final grades in mathematics for the S.Y. 2017-2018 were requested from their respective teachers.

\subsection{Data analysis}

Descriptive statistics such as means, frequencies, and percentages were used to describe the basic features of data in the study. The students' grades in mathematics were analysed following the descriptors prescribed by the Philippine Department of Education (DepEd) (Table 1).

Table 1. Descriptors, grading scale and remarks

\begin{tabular}{lll}
\hline Descriptor & Grading Scale & Remark \\
\hline Outstanding & $90-100$ & Passed \\
Very Satisfactory & $85-89$ & Passed \\
Satisfactory & $80-84$ & Passed \\
Fairly Satisfactory & $75-79$ & Passed \\
Did Not Meet Expectations & Below 75 & Failed \\
\hline
\end{tabular}

Source: 2019 DepEd K to 12 Grading System. Retrieved, 3 April 2020, from https://www.teacherph.com/deped-grading-system. 
Inferential analysis, such as the multiple linear regression was used to determine the influence of learning style and teaching strategies on academic performance. It specifically determines which among the learning styles and teaching strategies significantly influence the academic performance of Grade 9 students. Multiple linear regression (MLR) is the most common form of linear regression analysis. As a predictive analysis, the multiple linear regression is used to explain the influence between one continuous dependent variable and two or more independent variables (Kenton, 2019). The independent variables were categorical with dummy codes. In the study, the dependent variable was the average or final grade of the student respondents for the S.Y. 2017-2018, while the independent variables were learning styles and teaching strategies. In MLR analysis, the values of the intercept indicate the grade that a student will get if the learning styles and teaching strategies are zero or not available while the value of the slope determines the change in the value of the student academic performance for every change in the value of learning styles and teaching strategies.

\section{Results and discussion}

\subsection{Profile of the student respondents}

The students were composed of 133 (48 percent) male and 144 (52 percent) female. The majority or 95 percent of them were between 13-16 years old. Their average age is $15(\mathrm{SD}=0.89)$. In terms of their average or final grade in mathematics for the S.Y. 2017-2018, out of 277 student-respondents, 141 ( 51 percent) have the grade of 80 and below, 76 (27 percent) were in between 81-86 and those who have a grade of 87-92 are 53 (19 percent). Meanwhile, only 7 of them have a grade ranging 93 and above. This indicates that the majority of the student-respondents were performing between satisfactory and fairly satisfactory in mathematics.

\subsection{Learning styles of student respondents}

Table 2 shows that most of the student-respondents have a combination of dependent, collaborative, and participant learning styles. According to Samadi (2011), they are the students who enjoy working harmoniously with their peers. Meanwhile, 17 percent of the students have independent learning styles. Such students are more likely to prefer working alone (Fenrich, 2014). 
Table 2. Students' learning styles

\begin{tabular}{lll}
\hline Students' Learning Styles & f & \% \\
\hline Dependent & 83 & 30 \\
Collaborative & 64 & 23 \\
Independent & 48 & 17 \\
Participant & 45 & 16 \\
Competitive & 24 & 9 \\
Avoidant & 13 & 5 \\
Total & 277 & 100 \\
\hline
\end{tabular}

\subsection{Teaching strategies observed by student respondents to their teachers}

With regard to teaching strategies, most of the student-respondents agreed that demonstration and cooperative learning were commonly applied teaching strategies by their mathematics teachers (Table 3). Which is true, in teaching math subject there must be a demonstration before letting the students to do their own. Such demonstrations are so-called examples. According to Ramadhan and Surya (2017), the use of demonstration methods is effective in increasing students' mathematical ability, especially in mastering mathematical concepts on the matter of multiplication operations. The demonstration method increases the students' activeness and helps them in understanding the material, thus enhances their overall learning outcomes in mathematics.

Table 3. Observed teaching strategies by the student respondents

\begin{tabular}{lll}
\hline Teaching Strategies & f & \% \\
\hline Demonstration & 105 & 38 \\
Cooperative Learning & 43 & 16 \\
Inductive Approach & 39 & 14 \\
Lecture Type & 39 & 14 \\
Repetitive Exercise & 18 & 6 \\
Integrative Approach & 17 & 6 \\
Deductive Approach & 16 & 6 \\
Total & 277 & 100 \\
\hline
\end{tabular}




\subsection{Profile of the teacher respondents}

Table 4 presents the profile of the teacher respondents. Mathematics teachers were composed of three males and two females. From five teacher respondents, two were aged 20-29, another two were in between 30-39 years old and one of them was in between 40-49 years old. Most of them were teaching mathematics for more than five years and only one with 1-3 years of teaching experience.

Table 4. Profile of the teacher respondents

\begin{tabular}{llc}
\hline Demographic Profile & f & \% \\
\hline Age & & \\
\hline $20-29$ years old & 2 & 40 \\
$30-39$ years old & 2 & 40 \\
$40-49$ years old & 1 & 20 \\
$\mathrm{n}$ & 5 & 100 \\
\hline Sex & & \\
\hline Male & 3 & 60 \\
Female & 2 & 40 \\
$\mathrm{n}$ & 5 & 100 \\
\hline Civil Status & & \\
\hline Single & 3 & 60 \\
Married & 2 & 40 \\
$\mathrm{n}$ & 5 & 100 \\
\hline Number of years as a Math Teacher & & \\
\hline Less than a year & 0 & 0 \\
$1-3$ years & 1 & 20 \\
more than 5 years & 4 & 80 \\
$\mathrm{n}$ & 5 & 100 \\
\hline
\end{tabular}

\subsection{Teaching strategies applied by the teacher respondents}

Three teachers applied cooperative learning, only one applied demonstration, and the other one applied repetitive exercise. This validates the students' response regarding demonstration and cooperative learning as the most observed teaching strategies by their mathematics teachers. 


\subsection{Regression analysis}

This section presents multiple regression analyses between the dependent variable and independent variables.

The result of regression analysis (see Table 5 below) explicitly shows that among the learning styles, only the independent style has a significant influence on the academic performance of grade 9 students $(b=3.638, p=0.029)$. While those learning styles do not necessarily contribute to the level of their performance in Math subject are collaborative $(b=1.487, p=0.356)$, competitive $(b=2.638 p=0.148)$, dependent $(b=1.786 \mathrm{p}=0.285)$, and participant $(b=-2.043, p=0.221)$. Although other styles have something to do with their learning, but there is no effect on academic performance. In fact, it contributed 24 percent $\left(\mathrm{R}^{2}=0.236\right)$ to the variance in academic performance.

Table 5. The summary output of regression statistics of academic performance, learning style and teaching strategies

\begin{tabular}{lllll}
\hline \multicolumn{5}{c}{ Unstandardized } \\
Coefficients & Sig \\
\hline Learning style & b & Std. Error & t & S \\
\hline Constant & 80.154 & 1.466 & 54.690 & $1.970 \mathrm{E}-148$ \\
Collaborative & 1.487 & 1.608 & 0.925 & 0.356 \\
Competitive & 2.638 & 1.820 & 1.450 & 0.148 \\
Dependent & 1.786 & 1.576 & 1.133 & 0.258 \\
Independent & 3.638 & 1.652 & 2.202 & $0.029^{*}$ \\
Participant & -2.043 & 1.664 & -1.228 & 0.221 \\
\hline Teaching strategies & & & & \\
\hline Constant & 79.952 & 0.519 & 154.151 & $3.272 \mathrm{E}-265$ \\
Cooperative & 2.722 & 0.962 & 2.829 & $0.005^{*}$ \\
Deductive & 3.298 & 1.426 & 2.312 & $0.022^{*}$ \\
Inductive & 3.253 & 0.997 & 3.264 & $0.001^{* *}$ \\
Integrative & 5.283 & 1.389 & 3.802 & $0.000^{* *}$ \\
Lecture & 0.304 & 0.997 & 0.305 & 0.761 \\
Repetitive Exercise & 2.603 & 1.356 & 1.920 & 0.056 \\
\hline
\end{tabular}

**significant at the 0.01 level; *significant at the 0.05 level

On the other hand, four (4) teaching strategies have significant influence on the academic performance of Grade 9 students. These were cooperative learning, deductive approach, inductive approach and integrative approach with $(\mathrm{b}=2.722, \mathrm{p}$ $=0.005),(b=3.298, p=0.022),(b=0.001),(b=5.283, p=0.000)$, respectively. However, teaching strategies that did not contribute to increase the performance in 
Math subject were lecture type $(b=0.304, p=0.761)$ and repetitive exercise $(b=$ 2.603, $\mathrm{p}=0.056)$. Overall, teaching strategies have significant impact on the academic performance of the students, $\mathrm{F}(6,277)=5.160, \mathrm{p}<0.05)$. These contributed 51 per cent $\left(\mathrm{R}^{2}=0.508\right)$ to the variance in the academic performance.

This supports the findings of Akiri and Ugborugbo (2017), who showed that effective teachers produced better-performing students. However, due to the limitations of the study, the observed differences in students' performance were found not statistically significant. Thus, the study concluded that teachers' effectiveness is not the only determinant of students' academic achievement. But based on the study of Fayombo (2015), the teaching strategies and learning styles contributed 20 percent $\left(\mathrm{R}^{2}=0.20\right)$ to the variance in academic achievement, and this was statistically significant (F $(2,168),(21.04, \mathrm{p}<.05))$. These findings revealed the importance of utilizing different teaching strategies to accommodate different learning styles and improve students' academic performance in mathematics. To support the result, according to Khan and Javed (n.d.), teachers should understand learning styles and relate them to their own context. Analysing learning styles can be beneficial to students and might help them focus on learning, thus increasing educational outcomes and satisfaction.

Looking back to the response of the teacher respondents, most of them apply cooperative learning, which is being revealed in the regression analysis with a high significance level of influence in the performance of the grade 9 students. According to the study of Ganyaupfu (2013), the results demonstrate that teacher-student interactive method was the most effective teaching strategy, which is one of the features of cooperative learning, followed by student-centred method while the teacher-centred approach was the least effective teaching strategy which is shown in the lecture-type strategy. On the other hand, repetitive exercise has no influence on the performance of the students, but it gives the teacher another way of teaching mathematics.

\section{Synthesis of the Findings}

This study was conducted to understand the influence of learning styles and teaching strategies on the academic performance of grade 9 students. There were 277 studentrespondents from 991 population and five teacher-respondents who are teaching grade 9 Mathematics. In terms of the teaching strategy, mathematics teachers mostly applied cooperative learning. This was followed by a demonstration and repetitive 
exercise. This result had been validated by the students who agreed that cooperative learning and demonstration were applied by their teachers in teaching mathematics. In terms of the learning style, most of the students were collaborative.

Of all the learning styles, only an independent learning style has a significant influence on improving the academic performance of the students, whereas teaching strategies that have a significant influence on the academic performance of the students were cooperative learning, deductive approach, inductive approach, and integrative approach.

\section{Conclusions and implications}

The study provides discussions about the influence of student learning styles and teaching strategies on academic performance in mathematics. This adds to what the existing literature claims that to improve the academic performance of the students in mathematics, we must begin in knowing the students' learning style. Determining their learning styles will be a great help to teachers in designing and implementing a particular strategy that suits them. The following are some of the suggested strategies and techniques to improve the teaching and learning of mathematics:

For cooperative learning, mathematics teacher may explore the following techniques:

Think-Pair-Share as it allows students to engage in individual and small-group thinking before asking the questions in front of the class (Razak, 2016).

Round table or rally table. This is a simple cooperative learning strategy that covers those content-based topics, and it builds a spirit of cooperation and participation (Sari et al., 2019). This strategy has three steps. These include firstly; the teacher poses a question that has multiple answers. Secondly, the first student in each group writes one response on a paper and passes the paper counterclockwise/clockwise to the next student. And finally, the group with the greatest number of correct answers will gain some type of recognition.

Jigsaw. In this strategy, each member of the group is responsible for learning a specific part of the topic. Each member is called 'expert' because of what s/he knows in the given topic to him/her. Each expert discusses his/her findings and learnings to the group. By this strategy, the whole topic is discussed, and each student has mastery in the process of learning (Zakaria, et al., 2013).

For deductive, there should be a (i) clear recognition of the problem; (ii) search for a tentative hypothesis; (iii) formulation of a tentative hypothesis; and (iv) 
verification of the hypothesis. This is appropriate for giving practice to the student in applying the formula or principle or generalization which has already been arrived at. This method is very useful for the retention of facts and rules as at provides adequate drill and practice (Adunola, 2011).

For inductive, math teachers should incorporate the following techniques:

Presentation of Examples. Where math teachers present many examples of same type and provide solutions for those specific examples with the help of the students.

Observation. Using the examples and solutions, the students are engaged to make some conclusions.

Generalization. The teacher and students share their common observations and make a conclusion or a generalization about the principle and concept bound by logical explanations.

Testing and Verification. To check if the arrived conclusion is correct and acceptable, the students are to test and verify the principle and concept using the examples given. Through this method, the students attain the knowledge and logical explanations (Rahmah, 2017).

For integrative teaching, math teachers are encouraged to:

Incorporate the thematic and integrated curriculum in the daily schedule or weekly lesson plan. Adapt lesson plans for diversity, which means a lot to the different kinds of learners inside the classroom. Provide new interdisciplinary ways of presenting old topics like video presentations, project making, and hands-on.

Foster an atmosphere that welcomes and encourages creativity in the classroom. Design activities that require students to discover, manipulate, combine, and transform knowledge into useful creation.

Use age-appropriate materials and techniques in teaching mathematics. Interrelating the cognitive, affective, and psychomotor must be considered in preparing materials and activities that are appropriate to the age and maturity of the students (Adunola, 2011).

These are some of the practical ways by which mathematics teachers can make a difference in the academic life of students who find no intrinsic motivation in mathematics. This is something more that must be done and taken into greater account to be able to improve the academic performance of high school students in mathematics. If teaching and learning processes are working effectively, a unique kind of relationship must exist between those two separate parties-some kind of a connection, link or bridge between the teacher and the learner. By understanding the 
diversity of students, realizing their different learning styles, teachers will be guided in designing different strategies. These will help students learn the easier way and, thus, achieve better academic performance in mathematics.

\section{References}

Adunola, O. (2011). The Impact of Teachers' Teaching Strategies on the Academic Performance of Primary School Pupils in Ijebu-Ode Local Cut Area of Ogun State. Ego Booster Books, Ogun State, Nigeria.

Akiri, A. A., \& Ugborugbo, N. M. (2009). Teachers' Effectiveness and Students' Academic Performance in Public Secondary Schools in Delta State, Nigeria. Studies on Home and Community Science, 3(2), 107-113.

Altintas, E., \& Ilgün, S. (2017). Exploring the Opinions about the Concepts of" Formula" and" Rule" in Mathematics. Educational Research and Reviews, 12(19), 956-966.

Ariola A. (2012), Learner's Learning Preferences and Teaching Strategies in Mathematics of Fourth Year High School at Mabitac Laguna.

Atta, M. A., Ayaz, M., \& Nawaz, Q. (2015). Comparative study of inductive \& deductive methods of teaching mathematics at elementary level. Gomal University Journal of Research, 31(1), 2028.

Azarkhordad, F., \& Mehdinezhad, V. (2016). Explaining the students' learning styles based on Grasha-Riechmann's student learning styles. J Admin Manage Train, 12(6), 241-247.

Baig, F. (2015). Application of Teaching Methods in Mathematics at Secondary Level in Pakistan. Pakistan Journal of Social Sciences (PJSS), 35(2).

Baneshi, A. R., Karamdoust, N. A., \& Hakimzadeh, R. (2013). Validity \& reliability of the Persian version of Grasha-Richmann student learning styles scale. Journal of Advances in Medical Education \& Professionalism, 1(4), 119-124.

Baneshi, A. R., Tezerjani, M. D., \& Mokhtarpour, H. (2014). Grasha-Riechmann college students' learning styles of classroom participation: Role of gender and major. Journal of Advances in Medical Education \& Professionalism, 2(3), p. 103.

Bates, A. (2020). Basic Math Teaching Strategies. Retrieved o3 April 2020 from https://resilienteducator.com/classroom-resources/basic-math-teaching-strategies/

Chan, L. L., \& Idris, N. (2017). Cooperative learning in mathematics education. International Journal of Academic Research in Business and Social Sciences, 7(3), 539-553.

Coffield, F., Moseley, D., Hall, E., Ecclestone, K. (2004). Learning styles and pedagogy in post-16 learning: A systematic and critical review.

Department of Education (DepEd) (2019). DepEd K to 12 Grading System. Retrieved, 3 April 2020, from https://www.teacherph.com/deped-grading-system/

Dudovskiy, J. (2016). The ultimate guide to writing a dissertation in business studies: A step-bystep assistance. Pittsburgh, USA.

Fayombo, G. (2015). Learning Styles, Teaching Strategies and Academic Achievement among Some Psychology Undergraduates in Barbados. Caribbean Educational Research Journal, 3(2), 46-61.

Fonseca, J. R. (2007). Can We Reduce Students' Negative Attitude Towards Math? In SITE 2007: Informing Science+ IT Education Conference (Vol. 7).

Ford, J. H., Robinson, J. M., \& Wise, M. E. (2016). Adaptation of the Grasha Riechman Student Learning Style Survey and Teaching Style Inventory to assess individual teaching and 
learning styles in a quality improvement collaborative. BMC Medical Education, 16(1), p. 252.

Ganyaupfu M. E. (2013). Teaching Strategies and Students' Academic Performance. International Journal of Humanities and Social Science Invention, 2(9), 29-35

Goffe, W. L., \& Kauper, D. (2014). A survey of principles instructors: Why lecture prevails. The Journal of Economic Education, 45(4), 360-375.

Grasha, A. F. (1996). An Integrated Model of Teaching and Learning Style. Teaching with Style: A Practical Guide to Enhancing Learning by Understanding Teaching and Learning Styles. Alliance Publishers.

Grasha, A. F., \& Yangarber-Hicks, N. (2000). Integrating teaching styles and learning styles with instructional technology. College teaching, 48(1), 2-10.

Gujjar, A. A., \& Tabassum, R. (2011). Assessing learning styles of student teachers at federal college of education. Procedia-Social and Behavioral Sciences, 30, 267-271.

Hamzeh, M. A. W. (2014). Teaching Strategies Used by Mathematics Teachers in the Jordan Public Schools and Their Relationship with Some Variables. American Journal of Educational Research, 2(6), 331-340.

Hightower, A. M., Delgado, R. C., Lloyd, S. C., Wittenstein, R., Sellers, K., \& Swanson, C. B. (2011). Improving Student Learning by Supporting Quality Teaching.

Javed, A., Saif, N., \& Kundi, G. M. (2013). The Study of Effectiveness of Cooperative Learning Approach in Teaching of Mathematics at Secondary Levels in Pakistan. Mathematical Theory and Modeling, 3(10), 24-33.

Kenton, W. (2019). Multiple Linear Regression - MLR Definition. Retrieved 4th November 2019 from https://www.Investopedia.Com/Terms/M/Mlr.Asp

Khan, J., \& Iqbal, M.J. (2016). Effects of Learning Style on Achievement of Distance Learners.

Nzesei, M. M. (2015). A Correlation Study between Learning Styles and Academic Achievement among Secondary School Students in Kenya. University of Nairobi.

Padmavathy, R. D., \& Mareesh, K. (2013). Effectiveness of problem based learning in mathematics. International Multidisciplinary e-Journal, 2(1), 45-51.

Panicker, V. M. (2014). Teaching of Mathematics through Integrated Approach at Secondary Level for Value Inculcation.

Prayoga, T., \& Abraham, J. (2017). A psychological model explaining why we love or hate statistics. Kasetsart Journal of Social Sciences, 38(1), 1-8.

Rahmah, M. A. (2017). Inductive-Deductive Approach to Improve Mathematical Problem Solving for Junior High School. Journal of Physics: Conference Series, 812(1), IOP Publishing.

Ramadhan, N., \& Surya, E. (2017). The Implementation of Demonstration Method to Increase Students' Ability in Operating Multiple Numbers by Using Concrete Object. International Journal of Sciences: Basic and Applied Research (IJSBAR), 34(02), 62-68.

Razak, F. (2016). The Effect of Cooperative Learning on Mathematics Learning Outcomes Viewed from Students' Learning Motivation. JRAMathEdu (Journal of Research and Advances in Mathematics Education), 1(1), 49-55.

Samadi, M. (2011). Evaluation of the Psychometric Properties of the Questionnaire of Learning Style of Felder Solomanin Pre-High Schoolgirls. Educational Modern Approaches of Educational and Psychological Sciences, 13(1), 39-60.

Sari, D., Mulyono, M., \& Sri Noor Asih, T. (2019). Mathematical Problem Solving Ability Viewed from Extrovert Introvert Personality Types on Cooperative Learning Models Type Rally Coach. Unnes Journal of Mathematics Education Research, 8(2), 141-146. Retrieved from https://journal.unnes.ac.id/sju/index.php/ujmer/article/view/28019 
Shaari, A. S., Yusoff, N. M., Ghazali, I. M., Osman, R. H., \& Dzahir, N. F. M. (2014). The Relationship between Lecturers' Teaching Style and Students' Academic Engagement. Procedia-Social and Behavioral Sciences, 118, 10-20.

Singh, N. K., \& Yadav, A. K. (2017). Inductive and Deductive Methods in Mathematics Teaching. South East Asian Journal of Mathematics and Mathematical Sciences, 14(1), pp. 151-158.

Singh, V. (2017). Exploring the relationship between cognitive style and learning style with academic achievement of elementary school learners. Educational Quest-An International Journal of Education and Applied Social Sciences, 8(spl), 413-419.

Stewart, K. L., \& Felicetti, L. A. (1992). Learning Styles of Marketing Majors. Educational Research Quarterly, 15(2), 15-23.

Tebabal, A. \& Kahssay, G. (2011), The Effects of Student-Centred Approach in Improving Students' Graphical Interpretation Skills and Conceptual Understanding of Kinematical Motion. LatinAmerican Journal of Physics Education, 5(2), 374-381.

Tomlinson, C. (2001). How to differentiate instruction in mixed-ability classrooms. Alexandria, VA: Association for Supervision and Curriculum Development.

Tulbure, C. (2012). Learning styles, teaching strategies and academic achievement in higher education: A cross-sectional investigation. Procedia-Social and Behavioral Sciences, 33.

Valdez, D. B. (2016). Investigative Approach in Teaching System of Linear Equation and Inequalities to Grade 8 Students of Los Banos National High School - Batong Malake, Los Banos, Laguna.

Warthen, S. (2017). Instructional Strategies of Effective Mathematics Teachers of African American Upper Elementary Students.

Wilson, E. O. (1999). Consilience: The Unity of Knowledge (Vol. 31). Vintage.

Zakaria, E., Solfitri, T., Daud, Y., \& Abidin, Z. Z. (2013). Effect of cooperative learning on secondary school students' mathematics achievement. Creative Education, 4(2), 98-100. 


\section{Appendix 1}

\section{A. Students' Learning Styles' Questionnaire}

The following questionnaire has been designed to help you clarify your attitudes and feelings toward the mathematics. There is no right or wrong answers to each question. However, as you answer each question, form your answers with regard to your general attitudes and feelings toward mathematics.

Respond to the items listed below:

5 - Strongly Agree (SA)

$4-\operatorname{Agree}(\mathrm{A})$

3 - Moderately Agree (MA)

2 - Disagree (D)

1 - Strongly Disagree (SD)

\begin{tabular}{lccccc}
\hline \multicolumn{1}{c}{ Attitudes and Feelings toward Mathematics } & SA & A & MA & D & SD \\
& 5 & 4 & 3 & 2 & 1 \\
\hline 1. I am confident of my ability to learn important & & & & & \\
information in the subject. & & & & & \\
2. I often daydream during class. & & & & & \\
3. Working with other students on class projects is & & & & & \\
something I enjoy. & SA & A & MA & D & SD \\
\hline Attitudes and Feelings toward Mathematics & 5 & 4 & 3 & 2 & 1 \\
\hline
\end{tabular}

4. Facts presented in textbooks and lectures usually are correct.

5. To do well, it is necessary to compete with other students for the teacher's attention.

6. I am usually eager to learn about the content areas covered in class.

7. My ideas about content are often as good as those in the textbook.

8. Classroom activities generally are boring.

9. I enjoy discussing my ideas about the content of the subject with other students.

10. Teachers are the best judges of what is important for me to learn in the subject.

11. It is necessary to compete with other students to get a high grade.

12. Class sessions typically are worthwhile.

13. I study what is important to me and not always what the instructor says is important.

14. Sometimes, I do become excited about the materials covered in the subject.

15. I enjoy hearing what other students think about issues raised in class.

16. I like the way teachers state exactly what they expect from students.

17. During class discussions, I must compete with other students to get my ideas across.

18. I get more out of going to class than staying at home.

19. Most of what I know, I learned on my own.

20. I generally feel like I have to attend class rather than like I want to attend.

21. I can learn more by sharing ideas with one another. 
22. I try to do assignments exactly the way my teachers say they should be completed.

23. Students have to become aggressive to do well in school.

24. Everyone has a responsibility to learn more in the subject as much as possible.

25. I can determine for myself the important content issues in the subject.

26. Paying attention during class sessions is difficult for me to do.

27. I like to study for tests with other students.

\begin{tabular}{lccccc} 
Attitudes and Feelings toward Mathematics & SA & A & MA & D & SD \\
& 5 & 4 & 3 & 2 & 1 \\
\hline
\end{tabular}

28. Teachers who let students do whatever they want are not doing their jobs.

29. I like to get the answers to problems or questions before anybody else can.

30. Classroom activities generally are interesting.

31. I like to develop my own ideas about subject matter.

32. I have given up trying to learn anything from going to class.

33. The ideas of other students help me to understand the subject matter.

34. Students need to be closely supervised by teachers on all subject projects.

35. To get ahead in class, it is necessary to step on the toes of other students.

36. I try to participate as much as I can in all aspects of the subject.

37. I have my own ideas about how classes should be run.

38. In most of my class, I study just hard enough to get by.

39. An important part of the class is learning to get along with other people.

40. My notes contain almost everything the teacher said in class.

41. Students hurt their chances for a good grade when they share their notes and ideas.

42. Assignments are completed whether or not I think they are interesting.

43. If I like the topic, I usually find out more about it on my own.

44. I typically cram for exams.

45. Learning should be cooperative effort between students and teachers.

46. I prefer class sessions that are highly organized.

47. To stand out in my classes, I try to do assignments better than other students.

48. I complete my assignments soon after they are given.

49. I prefer to work on class related projects (e.g. studying for exams, papers) by myself.

50. I would like teachers to ignore me in class. 


\section{Attitudes and Feelings toward Mathematics}

51. I let other students borrow my notes when they ask for them.

52. Teachers should tell students exactly what material is going to be covered on a test.

53. I like to know how well other students are doing on exams and assignments.

54. I complete required reading requirements as well as those that are optional.

55. When I don't understand something, I try to figure it out for myself before seeking help.

56. During class, I tend to talk or joke around with people sitting next to me.

57. Participating in small group activities in class is something I enjoy.

58. I find teacher outlines or notes on the board very helpful.

59. I ask other students in class what grades they received on tests and assignments

60. In my classes, I often sit towards the front of the room.

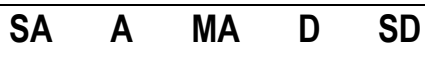

$\begin{array}{lllll}5 & 4 & 3 & 2 & 1\end{array}$




\section{B. Teaching Strategies Questionnaire}

The following statements are the ways how your teacher teaches mathematics.

Respond to the items listed below:

$$
\begin{aligned}
& 5 \text { - Always (AL) } \\
& 4 \text { - Often (O) } \\
& 3 \text { - Sometimes (ST) } \\
& 2 \text { - Seldom (SD) } \\
& 1 \text { - Never (N) }
\end{aligned}
$$

\section{Teaching Strategies Applied by the Teacher}

$\begin{array}{ccccc}\mathrm{AL} & 0 & \mathrm{ST} & \mathrm{SL} & \mathrm{N} \\ 5 & 4 & 3 & 2 & 1\end{array}$

1. Teacher uses specific questions to discuss the whole topic.

2. Teacher awards students for their right answer.

3. Teacher provides students feedbacks regarding their answer at all times.

4. Teacher uses direct presentation to provide students with information.

5. Teacher trains students to determine the whole idea of the topic.

6. Teacher makes advantage of providing different activities to secure the teaching - learning process.

\section{Teaching Strategies Applied by the Teacher}

$\begin{array}{lllll}\text { AL } & 0 & \text { ST } & \text { SL } & \text { N }\end{array}$

7. Teacher dissembles the teaching - learning material into specific tasks that need specific responses.

8. Teacher depends on criteria in evaluating his students.

9. Teacher cares about correcting students by providing many worksheets.

10. Teacher neglects undesired behaviors in the teaching - learning situations.

11. Teacher helps his students imitate desired models by showing it.

12. Teacher provides students with a chance to apply new knowledge in new real life situations.

13. Teacher trains his students on distinguishing between different characteristics of the same concept.

14. Teacher trains students on learning the whole concept before the specific idea.

15. Teacher gives similar examples during the discussion to secure the mastery of the topic.

16. Teacher encourages students to work with others to generate as many alternatives as they can for the problem discussed.

17. Teacher begins with presenting main ideas of the topic at the beginning of the class.

18. Teacher ends teaching - learning situation with connecting the lesson parts together.

19. Teacher begins the teaching - learning situation with presenting a problem to students.

20. Teacher uses specific problem solving strategy in the teaching process.

21. Teacher gives students enough time to think and to investigate with others to achieve desirable 
objective.

22. Teacher ends teaching - learning situation with clarifying and discussing diagrams suitable for students.

23. Teacher makes use of concept maps during the teaching - learning process.

24. Teacher takes part in training students by providing different learning activities.

25. Teacher trains students on generating specific answers for the questions raised to them.

26. Students tend to generate new information through making comparison between their previous knowledge and new one.

\section{Teaching Strategies Applied by the Teacher}

$\begin{array}{lllll}\text { AL } & 0 & \text { ST } & \text { SL } & \text { N }\end{array}$

27. Teacher trains students to plan, observe, and evaluate their teaching activities.

28. Teacher shows students how to verify information and facts before giving judgments.

29. Teacher gives students a chance to generate new concepts.

30. Teacher facilitates students to make use of the procedures that organizes memory potentials (symbolizing information).

31. Teacher helps students identify their own mistakes by doing similar worksheets.

32. Teacher's cognitive teaching strategies harmonize with students' learning strategies.

33. Teacher guides students to references such as dictionaries, encyclopedias, internet sites, etc.

34. Teacher moves from the abstract to the concrete examples.

35. Teacher begins with examples up to the concept in the teaching - learning situation.

36. Teacher asks students to do written or verbal summaries of the information they get.

37. Teacher applies group work in the class to serve desired objectives.

38. Teacher distributes different teaching - learning tasks on students.

39. Teacher lets students have their own conversations positively.

40. Teacher allows students to have more clarifications and explanations on a certain topic.

41. Teacher supports students in using different learning tools for the purpose of teaching - learning process.

42. Teacher assigns students in a specific task into a general task.

43. Teacher encourages students to interact positively amongst themselves.

44. Teacher trains students to solve their problems in a comfortable way.

45. Teacher gives students the chance to correct their mistakes by answering similar question.

46. Teacher makes students take part in different roles 
in the teaching - learning situation.

\section{Teaching Strategies Applied by the Teacher}

$\begin{array}{lllll}\text { AL } & 0 & \text { ST } & \text { SL } & \text { N }\end{array}$

$\begin{array}{lllll}5 & 4 & 3 & 2 & 1\end{array}$

47. Teachers trains students by providing different sets of worksheets.

48. Teacher helps students to analyze the main idea to be used in discussing the topic as a whole.

49. Teacher teaches students the way to identify those simple tricks to understand the lesson. 


\section{Scoring Key of Learning Styles and Teaching Strategies}

Instruction: The numbers below represent the items in the questionnaire that correspond to each of the learning style and teaching strategy dimensions on the questionnaire.

A. To self-score this questionnaire, place the ratings you assigned to each item in the space provided. Get the sum of each column to determine your learning styles.

\begin{tabular}{|c|c|c|c|c|c|}
\hline Independent & Avoidant & Collaborative & Dependent & Competitive & Participant \\
\hline 1 & 2 & 3 & 4 & 5 & 6 \\
\hline 7 & 8 & 9 & 10 & 11 & 12 \\
\hline 13 & 14 & 15 & 16 & 17 & 18 \\
\hline 19 & 20 & 21 & 22 & 23 & 24 \\
\hline 25 & 26 & 27 & 28 & 29 & 30 \\
\hline 31 & 32 & 33 & 34 & 35 & 36 \\
\hline 37 & 38 & 39 & 40 & 41 & 42 \\
\hline 43 & 44 & 45 & 46 & 47 & 48 \\
\hline 49 & 50 & 51 & 52 & 53 & 54 \\
\hline 55 & 56 & 57 & 58 & 59 & 60 \\
\hline
\end{tabular}

B. To self-score this questionnaire, place the ratings you assigned to each item in the space provided. Get the sum of each column to determine which teaching is most applied by your teacher.

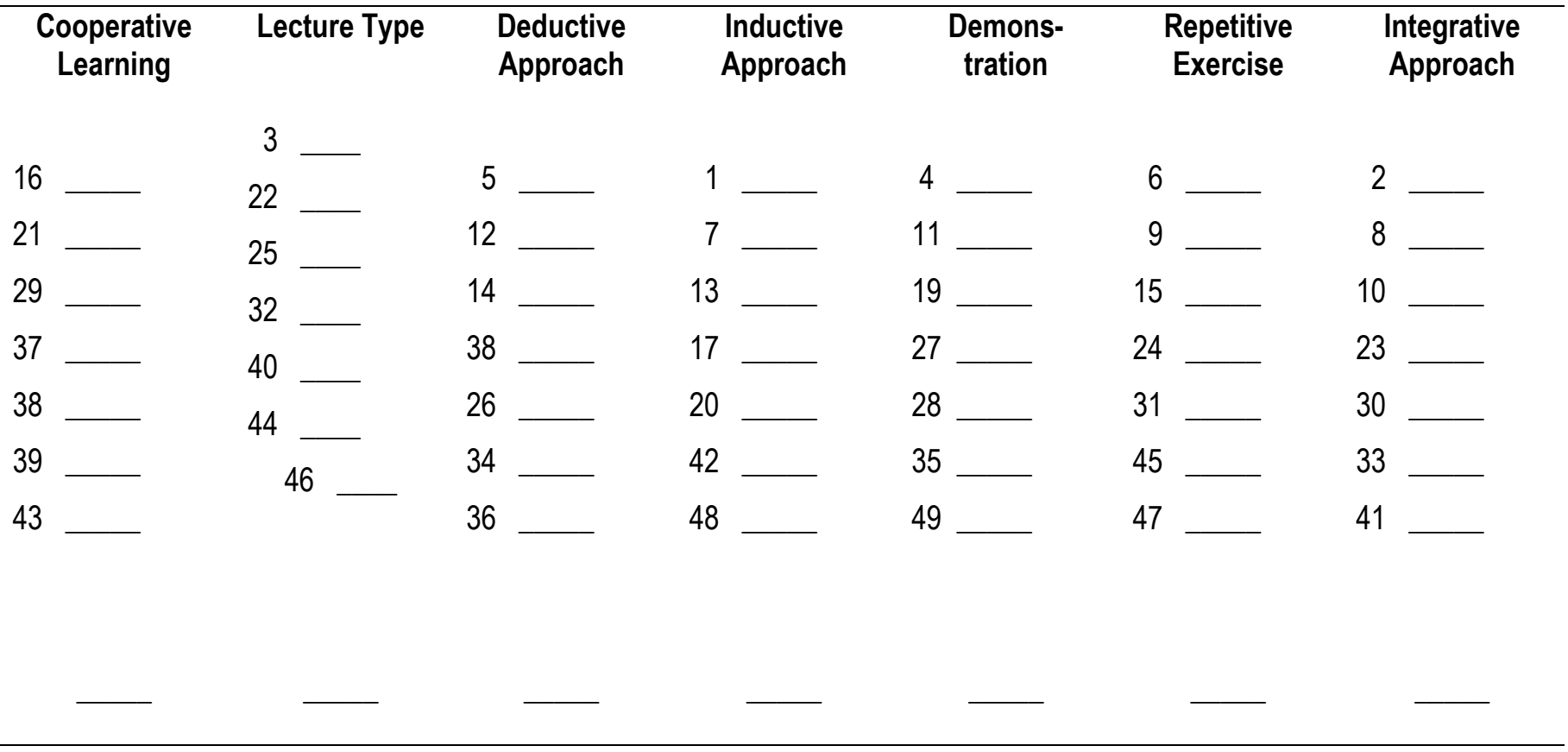

